\title{
Using Contradictions to Ravel Teaching and Learning Challenges in a Blended IS Course in an African University
}

\author{
Patient Rambe \\ Writing Centre, University of Cape Town, \\ Cape Town, South Africa \\ pjoerambe@gmail.com or p.rambe@uct.ac.za
}

\begin{abstract}
Although university students are immersed in Facebook interactions, little is known about the impact of these Social Media on lecturers' pedagogical strategies and student learning. Using Cultural Historical Activity Theory's (CHAT) notion of contradictions, this paper examines the influence of Facebook on lecturers' teaching strategies and student learning in a blended Information Systems course at a middle-sized African university. The research employed a multi-method approach that corroborated data from in-depth semi-structured interviews, in-class observations, and post-observation debriefings to unravel lecturers and students' experiences of Facebook use for teaching and learning. Several contradictions emerged from their Facebook use, namely, tensions between lecturers' teaching strategies and student conceptions of learning, dilemma between recruitment of student academic participation on Facebook and prevention of its resentment by uncooperative students, challenges of redundant postings, limitations of collective responsibility, intergenerational tensions between lecturers and students, and constraints of time. The findings include shifts from implicit to explicit teaching, pedagogical change from setting academic engagement rules to student persuasion to participate on Facebook, shifts from private academic support to consultation in public online spaces, and development of a collegial, mutually-beneficial consultative environment. Students reported ambivalent experiences of Facebook use with implications on lecturers' pedagogical strategies.
\end{abstract}

Keywords: Computer assisted instruction, Facebook, Cultural Historical Activity Theory, pedagogical strategy, contradictions

\section{Introduction}

As university student interaction and sharing of electronic resources in Web-enabled environments are becoming an embedded practice (Ng'ambi \& Rambe, 2008), educators are under pres-

Material published as part of this publication, either on-line or in print, is copyrighted by the Informing Science Institute. Permission to make digital or paper copy of part or all of these works for personal or classroom use is granted without fee provided that the copies are not made or distributed for profit or commercial advantage AND that copies 1) bear this notice in full and 2) give the full citation on the first page. It is permissible to abstract these works so long as credit is given. To copy in all other cases or to republish or to post on a server or to redistribute to lists requires specific permission and payment of a fee. Contact0HPublisher@InformingScience.org to request redistribution permission. sure to evolve pedagogical approaches (Salmon, 2007) that could support and leverage these forms of interactions. However, educators' implementation of Web-enabled courses for first year university students is often constrained by varying student academic underpreparedness, large classes, and inadequate curriculum design (Jaffer, Ng'ambi, \& Czerniewicz, 2007) and student incapacity to learn when con- 
fronted with a learning environment that requires an unfamiliar degree of initiative and autonomy (Tan \& Chan, 1997). The latter is the case for Social Media-enhanced learning environments that often put additional cognitive demands on learners to generate, share, and meaningfully engage with Web content, notwithstanding their underdeveloped self-regulation and learning abilities. Social Media denotes an aggregate of Web 2.0 based tools, applications, business models, and social networking that allows people to collaborate in novel ways at a large scale (Leadbeater, 2007). Instances of Social Media encapsulate social networking sites, blogs, podcasts, multimedia sharing sites, and aggregation tools.

Pargetter et al. (1998) suggest that students consistently identify independent learning and selfdiscipline as basic goals of their university education, although many are unsure about how to achieve those goals. In Social Media where there is limited lecturer-student direct interaction, not only are students challenged by using social networking applications for meaningful learning, but rather how self-directed learning can be fostered in these quasi-formal learning spaces. As Dabbagh and Kitsantas (2005) suggest, in Web-based learning environments, the physical absence of the instructor and the increased responsibility demanded of learners to effectively engage with learning tasks may present difficulties for learners, particularly those with low self-regulatory skills. The challenge, therefore, is grasping how Social Media like Facebook could impact student conceptual and practical understanding of Information Systems (IS) if it was appropriated for teaching and learning. Mindful of the uptake of these technologies in South African universities for sharing academic information, responding to student queries and building trust among academic communities (Moore, 2010), exploring the implications of implementing them in university is essential to effective pedagogical delivery.

The South African government expects Information Systems (IS) education to produce technically competent graduates who not only know how to effectively apply Web-based technology for their lifelong learning, but also understand how to appropriate it to solve complex workrelated problems. Emphasising the social relevance of higher education training to nation development, the South African White Paper on Higher Education (Republic of South Africa, 1997) reiterates the need to develop professionals and knowledge workers with globally equivalent skills and who are conscious of their role in contributing to national development. As Shen, Lee, and Tsai (2007) comment, a vocational education system constantly involves meeting the needs and the new demand for highly skilled manpower, the continued progress of modern technology, the worldwide economic development, and the changing industrial structure. The above points out the central role that technological skills play in the structural dynamics of national development in addition to psychological development. The challenge however for IS practitioners is designing learning environments that afford the acquisition and development of sophisticated IS skills and respond to the learning needs of university learners. Graetz (2006) argues that the migration of content which lecturers traditionally delivered in lecture format to the Web is helping shift the function served by brick and mortar classrooms from information delivery to collaboration and discussion. Yet these demands for collaboration and critical engagement in Web-enabled courses impose pressure on IS practitioners to respond to information demands of IS users and students and to develop a shared understanding of the role of technology in supporting collaborative teaching and solving students' learning challenges.

From an instructor point of view, there are barriers to effective implementation of Web-enabled courses such as the limited technical expertise of academics for effective integration of Webenabled courses into the curriculum. Therefore, while academics may be passionate about appropriating Social Media like Facebook for teaching, there may be conceptual challenges of integrating the technology into the mainstream curriculum and how it supports classroom teaching. Some barriers to Web-enabled teaching and learning in university include lack of critical reflection of teaching and learning using technology, unfamiliar teaching and developmental approaches, and 
the time investment needed to learn how to integrate Information and Communications Technologies (ICTs) effectively into teaching and learning activities (McIntyre, 2008; Van der Merwe \& Mouton, 2005). To guard against "technopositivism" (Njenga \& Fourie, 2010, p. 200), where unsubstantiated emphasis is placed on the technology rather than its pedagogical benefits, critical questions should be posed on how the Web application impacts the teaching and learning of students, particularly those with limited technological skills.

In light of the aforementioned pedagogical challenges that accompany the implementation of Web-enabled courses, this study investigates how three Information Systems (IS) lecturers' use of Social Media (in particular, Facebook) affected their teaching strategies and their students' learning experiences. Using Cultural Historical Activity Theory's (CHAT) notion of contradictions, the study examines the dilemmas these lecturers experienced in teaching a blended IS course and how these contradictions catalysed pedagogical innovation and change in students' learning practices. While a handful of studies examined the notion of contradictions (Barab, Barnett, Yamagata-Lynch, Squire, \& Keating, 2002; Engeström, 2000; Murphy \& Rodríguez-Manzanares, 2008b; Roth \& Lee, 2007), these studies were conducted in high school contexts (Murphy \& Rodríguez-Manzanares, 2008a) and did not examine blended learning contexts involving social networking environments. Using a blended learning course (combined face-to-face lectures with a Facebook environment) as a case study, a multiple method framework that corroborated data from in-class observations, post observation de-briefings with lecturers, and in-depth semistructured interviews with students and lecturers was employed to unpack the influence of Facebook on lecturers' teaching and undergraduate students' learning. These constructivist learning environments are worthy of study as they take advantage of emerging technologies to immerse students within contexts that challenge, ground and ultimately, extend their understandings (Barab et al., 2002). However, we are also mindful of the original branding Facebook as an identity construction, self-promotion and communicative space rooted in the domain of individual autonomy that complicates its application in perceivably instructivist learning environments of universities.

That said, the peculiarity of Facebook was derived from the fact that: 1. Student consultation was deemed not necessarily lecturer-dependent (students could consult with peers and senior students in addition to the online administrator), 2. Consultation was not time-dependent (students could consult any time, anywhere, during official working hours), 3. Facebook created a quasi-formal learning environment where consultations were not limited to scholarly issues. As such, the lecturers' expectation was to foster a knowledge-centred learning environment that was not educator directed. Creating participatory, blended learning environments has gained currency in education technology studies given social interaction's (face-to-face and mediated) capacity to foster meaningful learning experiences and develop higher psychological functions (Engeström, 1987; Kozulin, Gindis, Ageyev, \& Miller, 2003).

\section{Facebook Phenomenon}

Mark Zuckerberg, a Harvard University student, created Facebook as a social networking site (SNS) that connected university students with contact university e-mail addresses. Charnigo and Barnett-Ellis (2007) highlight that although originally created to allow students to search for other students at universities; the site has expanded to allow individuals to connect in high schools, companies and within regions. Therefore, Facebook affords students the opportunity to generate their own informal network of friends with whom they share resources (academic and social), friendship connections and social practices.

A growing body of literature investigated different aspects of Facebook ranging from its capacity to engender social capital formation (Ellison, Steinfield, \& Lampe, 2007), promote identity management and foster faculty relations (DiMicco \& Millen, 2007; Hewitt \& Forte, 2006), promote 
social integration and informal learning (Madge, Meek, Wellens, \& Hooley, 2009; Selwyn, 2007), and privacy considerations (Boyd, 2007; Grude, Scholl, \& Thompson, 2006). The limited number of studies that investigated informal learning on Facebook (Madge et al., 2009; Selwyn, 2007) have not used Cultural Historical Activity Theory (CHAT) to explore the possibilities for pedagogical change and innovation. More so, these studies were not anchored in blended learning environments.

Facebook learning environment is different from traditional didactic teaching for several reasons:

1. The learning environment is 'student controlled', that is, students control who can access their profiles, web page messages, and who inscribes on their walls. This individualised learning space however, does not preclude horizontal networking with peers within one's online network.

2. The space enables formal learning through possibilities for attachment and transmission of academic documents, and informal 'playful' learning through socialisation.

3. Unlike lectures, which are controlled, irretrievable communicative events (except when podcast or video recorded), Facebook interactions and conversations are backtracked by reviewing the conversation trails.

4. Communicative agents have a social presence of one another. Resultantly, this online visibility potentially engenders synchronous conversations between communicants (student-peer, lecturer-student), allowing for probing, constructive critique, and challenging of communicants' views.

Therefore, the academic networking community afforded by Facebook is worth studying given its potential to support a constructivist-learning environment and possibilities for fostering student psychological development. As Bishop-Russell, Dubord, Hansen, and Webster (2006) reiterate, Facebook's online community meets the requirements set forth by Chickering and Reisser (1993) for an environment that promotes student development by providing regular interaction between them and opportunities for collaboration with people from diverse backgrounds and by serving as a social reference group.

\section{Theoretical Framework}

\section{Cultural Historical Activity Theory (CHAT)}

CHAT constitutes a system of views initially formulated within the collaborative investigative project by Vygotsky, Leontiev, Luria, and several scholars in the early 20th century in Russia (Stetsenko, 2005). It explicates learning and, subsequently, development as socio-historically constituted activities fostered through social interaction of human beings and as artefact-mediated psychological processes. Arguably, the foundation of systematic thought about CHAT lies in Vygotskian notions of cultural development and mediated action. Vygotsky's thesis is that cultural development originates from the social world and progresses into the individual where internalisation and transformation occur through mastery of knowledge. His general genetic law of cultural development emphasises that:

Any function in the child's cultural development appears twice, on two planes. First it appears on the social plane, and then on the psychological plane. First it appears between people as an interpsychological category, and then within the child as an intrapsychological category (Vygotsky, 1930/1981, p. 163).

Therefore, social interaction mediated by psychological tools is critical to human psychological functioning and development. In fact, semiotic tools (like language and verbalisation) and cultural 
artefacts (technology, for example, Facebook) constitute the material artefacts through which humans draw on and learn about the social world. As such, CHAT offers a more realistic, theoretical framework for examination learning activities in technology-rich learning contexts.

Chat system affords a holistic examination of the object of activity ${ }^{1}$, its history and evolution, all in context. This renders the researcher an understanding of the object and the subjects who partake in it, how subjects' motives and the object itself co-evolve over time, and explanations for deviations from expected outcomes. In Activity Theory, Koszalka (2002) highlights, each activity is analysed as part of the collective and with a socio-historical context of the individual and of the collective, and hence CHAT. Therefore, the lecturer's involvement in instructional activities is not examined in isolation but rather as an integral part of a collection of other activities like the meditational tools employed in instruction, student engagement with content taught and other community members in academia. Hence, a holistic perspective on the analysis of activity systems is considered. CHAT, therefore, overcomes the Cartesian, dualistic thinking inherent in cognitive psychology where the mind is studied independent of the social context in which it functions. Cognitive psychology is critiqued for its ignorance of the determining role of real life processes, especially their social dimension in psychological functioning and ignoring the mental aspect or postulating it as a separate realm, independent of these processes (Stetsenko, 2005).

CHAT overcomes the dualistic body-mind and individual-culture splits characteristic of many approaches within psychology and sociology (Roth \& Lee, 2004). To the extent that CHAT values social interaction of human agents (both lecturers and students are co-participants in the learning process) as critical to learning, CHAT serves as a fundamental tool for examining these co-participants in situated contexts.

While CHAT is a useful theory for analysing the influence of structural and contextual forces on meaningful academic interaction, the theory is limited with regards operationalising relational power. Yet, the exercise of power is inherent in hierarchical academic discourses, typical of those that unfold in Social Media. As Toomela (2008) contends, one weakness of Activity Theory is that its focus on activities ignores an important aspect of the human mind, that is, externally the same behaviour can emerge from qualitatively different mental operations. Mindful of the fact that power in academic interactions can be exercised through interactants' control of their referent persons' mind, CHAT could be inadequate for examining power expressed through psychological (cogitative) control. The triangulation of data sources and research participants was deemed to complement the weakness of CHAT at the level of data collection and analysis.

\section{The Principle of Contradictions}

The notion and character of contradictions have been controversial in research studies that adopted the Activity Theory tradition (Barab et al., 2002; Engeström, 2000; Murphy \& Rodríguez- Manzanares, 2008b; Roth \& Lee, 2004). The concept is described as tensions among activity system components that explain what motivates particular actions and are useful in understanding the evolution of a system more generally (Barab et al., 2002; Russell \& Schneiderheinze, 2005). Other authors have conceived it as "problems, ruptures, breakdowns, clashes" in activities (Kuutti, 1996, p. 34).

Engeström's expansive learning cycle envisions change to happen through the intervention of a change laboratory. As such, his conception of contradictions has a professional work place inclination. As Hasu \& Engeström (2000, p. 65) suggest:

\footnotetext{
${ }^{1}$ Object of activity denotes the physical or conceptual material that drives human conscious involvement in activities. For Hasu and Engeström (2000, p. 63), the object refers to the "raw material" or "problem space" at which the activity is directed and which is molded or transformed into outcomes with the help of physical and symbolic, external and internal tools (mediating instruments and signs).
} 
Contradictions manifest themselves in disturbances and breakdowns in work processes as well as in workers innovative attempts to solve them. The notion of breakdown has been used to refer to a disruption in the normal functioning of things forcing the individual to adopt a more reflective or deliberative stance toward ongoing activity [...] Disturbances are analysed as deviations from this scripted procedure.

Contradictions thus force subjects to develop a new orientation towards the object and manifest in disturbances that trigger shifts in established work practices. My use of contradictions as an analytical tool differs in function from Engeström's change laboratory orientation. I use contradictions to analyse tensions between different activity elements as impetuses for changes in pedagogical practices and student learning and not as development research for practitioners, as in his work.

Although some of the aforementioned studies using Activity Theory as an investigative and analytical tool describe technology rich learning environments (Barab et al., 2002; Engeström, 2000; Russell \& Schneiderheinze, 2005), they are not rooted in higher educational contexts (Engeström, 2000; Russell \& Schneiderheinze, 2005) and do not unfold in SNS environments. While I recognise Engeström's $(1987,2001)$ work as central to Activity Theory advancement, I however use Russell \& Schneiderheinze's (2005) analytical framework for examining in-class and Facebook learning activities. Their analytical framework fits the intent of my research: 1) to track and monitor student interaction on Facebook as a basis to infer their learning trajectory and development changes, 2) to understand changes in lecturers' teaching strategies as a basis for scaffolding student learning in SNS.

\section{Methodology}

\section{Case Study}

This study employed an ethnographic case study approach. Schensul, Schensul, and LeCompte $(1999$, p. 5) observe that ethnographic research focuses on understanding a population in a broader socio-economic and political context and this understanding is important in order to situate local experience and cultural observations. Mindful of my goal to unpack how Facebook use by lecturers and students impacted their pedagogical strategies and learning in tertiary learning contexts respectively, understanding the lecturers and students' individual experiences and interpretations of their academic 'life worlds' was critical to locating these experiences in context.

The study was conducted on three first year IS lecturers who taught three undergraduate classes at a middle-sized South African university. The first class was the INF1002H comprising about 50 students from the Academic Development Programme (ADP) who had limited or no prior ICT skills and some had English language problems. The second course, INF1002F, comprised 800 students with sophisticated ICT skills and was split into two classes. The methodological choice of IS students was informed by the fact that this was the only academic stream in the university that engaged in lecturer-student academic consultation using SNS (Facebook). More so, selecting Facebook for research was guided by the assumption that IS students possibly derived academic value from its use given their social immersion in it.

The three classes covered the same course material, although the INF1002F students finished the course in the first semester given their prior exposure to ICTs. The INF1002H group was on an extended IS curriculum course conducted for one year. To ensure that trends and shifts in teaching practices were well tracked and documented, the two classes were observed for the duration of their courses, that is, one semester (for 4 months) and two semesters ( 8 months) for INF1002F and INF1002H groups respectively. In total, I5 in-class observations were conducted over this duration. Each observation lasted 45 minutes - the duration of a lecture session. 
Apart from lectures, these classes had Web-supplemented learning resources (lecture slides, additional readings, test, and practical schedules) posted on the university's instance of Sakai based learning management system. One regular lecturer who taught both groups created an IS group on Facebook and students were required to create Facebook accounts and to join the group. A course convenor maintained a social presence on the Facebook group and offered limited administrative support to students upon request. The other lecturer posted announcements and quasi academic information on the departmental blog (another form of Social Media). The regular lecturer, however, assumed the online course instructor's role of addressing academic queries and questions students raised during the normal working hours $(8 \mathrm{am}-430 \mathrm{pm})$. Notwithstanding the differential levels of prior exposure to ICTs in high school, all students interacted on the same Facebook site. Students consulted with the lecturers on theory, practical, and course administration issues. They had three options on Facebook for consulting with the online administrator and with peers: the administrator's inbox, discussion board, and the wall. Sometimes, students also consulted with the course convenor via the departmental Facebook wall.

\section{Research Participants}

Of the 850 IS students, there were 165 participants on Facebook, and these posted 414 posts. These participants posted 154 wall posts, 121 discussion board posts, and 139 posts to the administrator's inbox.

For in-depth interviews, my research participants were 46 IS students (14 students from INF1002H and 32 from INF1002F) and their three lecturers. Students were interviewed on their experiences of academic use of Facebook and implications of their use for learning. The three lecturers I observed during their lessons had taught students for a duration long enough (two semesters) to allow me to trace changes in their teaching practices and to identify the resultant contradictions that emerged. The table below summarises the lecturers investigated, the students they taught, and the technologies they used in class and beyond.

Table 1: Participants in the study

\begin{tabular}{|l|l|l|}
\hline Educator & Students & Technologies used \\
\hline Lecturer A & $\begin{array}{l}\text { Mainstream and ADP } \\
\text { classes }\end{array}$ & $\begin{array}{l}\text { Facebook, blogs, discussion forums on the LMS, } \\
\text { Multimedia (laptop run Facebook, interactive } \\
\text { white board, data projector), microphones }\end{array}$ \\
\hline Lecturer B & $\begin{array}{l}\text { Mainstream classes } \\
\text { and ADP class }\end{array}$ & $\begin{array}{l}\text { Facebook, blogs, discussion forums on the LMS, } \\
\text { Multimedia, microphones }\end{array}$ \\
\hline Lecturer C & Mainstream class & $\begin{array}{l}\text { Blogs, Vula discussion forums, and interactive } \\
\text { whiteboard, data projector, microphones }\end{array}$ \\
\hline
\end{tabular}

Using an Activity theoretical framework, I summarised the object of using Facebook, tools-inuse, the subjects, the community, roles, rules, and outcomes of learning where Facebook was involved. 


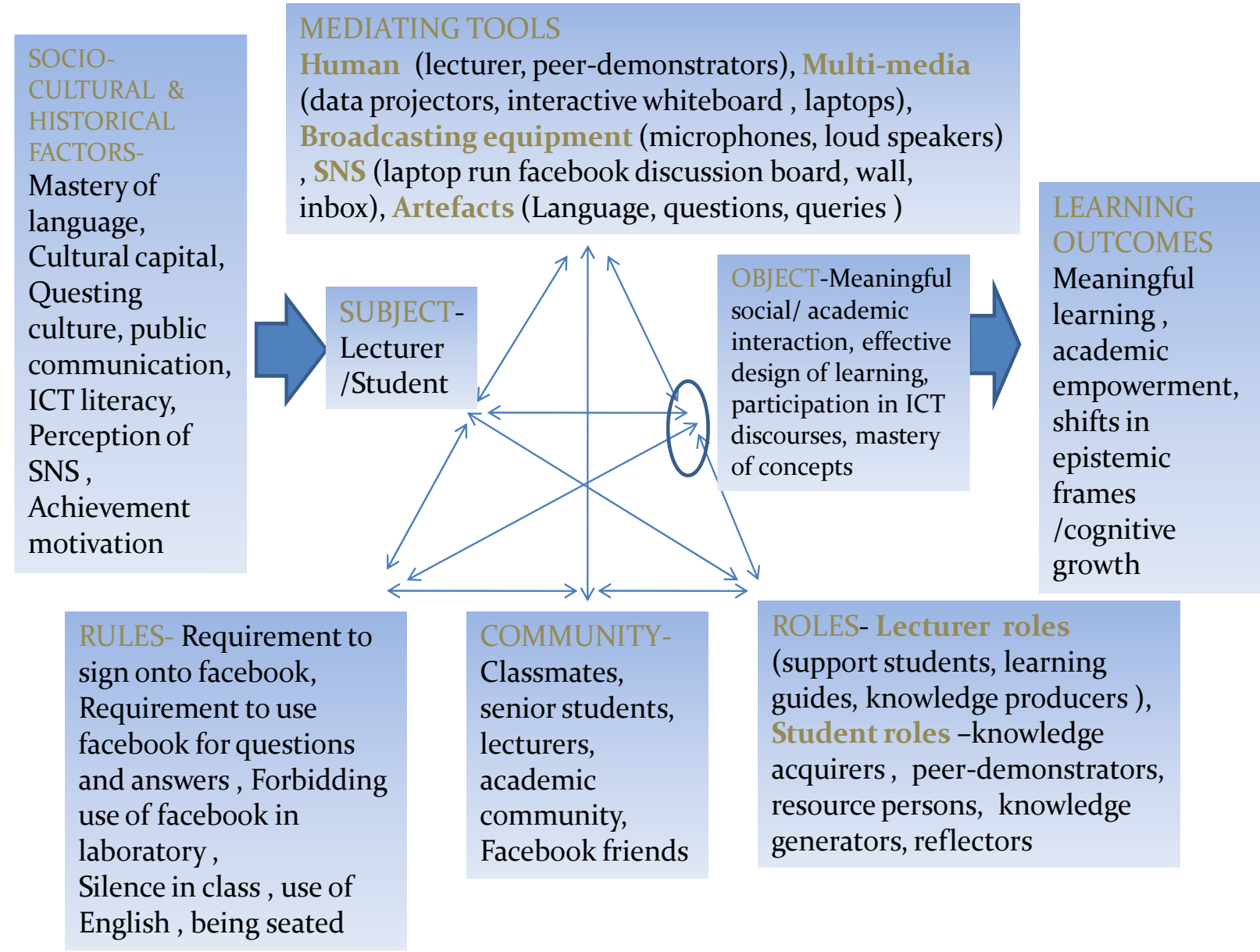

\section{Figure 1: Summary of Activity Theory elements of face-to-face lectures and Facebook interactions}

\section{Data Analysis}

Russell \& Schneiderheinze's (2005) analytical framework suggests that research questions be developed during data structuring to aid the researcher in understanding how subjects (lecturers/students) responded to the activity implementation process (Facebook enabled interaction). Russell \& Schneiderheinze suggest that an activity system analytical framework should involve the following stages:

1. A detailed description of the subjects' experience of participating in the work activity over an extended time frame, drawing upon multiple sources. My research examined the pedagogical activities of three lecturers, two of whom used Facebook for student consultation over a period of approximately two semesters. My multi-source framework combined lecturer and student interviews, observations, post observation debriefings with lecturers to gain insights into the activity under discussion (Facebook interaction's impact on pedagogical strategy and learning).

2. The researcher identifies the nodes of the subjects' work activity system and creates the Activity Theory (AT) Model for each subject using the subjects' voice in both her collaborative interaction with the other subjects and in his/her reflective dialogue with the researcher. I created three AT models for the three lecturers based on their interaction with students on Facebook (and blogs) and on my interviews with them. 
3. The researcher identifies contradictions occurring in the development of the object, as perceived by the subject, and categorizes them as contradictions she can or cannot resolve. I identified unresolved contradictions on the model using a solid broken arrow, resulting in the lessening of the potential of the subject to develop her object, or as a dashed broken arrow when the subject identified the contradiction and resolved it, resulting in the increased possibility that she would meet her object goals.

4. The researcher identifies the turning points indicating how she responded to the contradiction and, subsequently, the way her response influenced the transformation of object, the manner of implementation. As a result, the researchers could identify case-by-case contradictions and turning points, which resulted in widening, narrowing, or disintegrating of the object (Russell \& Schneiderheinze, 2005, p. 43)

In my intention to trace the origin of artefacts posted on Facebook, I examined classroom interactions. Russell \& Schneiderheinze (2005) analytical framework's capacity to track the evolution of activity systems allowed me to develop conceptual models of individual lecturer's activity systems, identify activity contradictions and their resolution as forces for change in the object sought, or change in activity elements or work practices.

\section{Results Examination of Contradiction}

\section{Lecturer A's Teaching Strategy and Conception of Learning}

Lecturer A's object was to design learning activities in ways that ensured student mastery of Microsoft Excel concepts, perfected their acquisition of Excel skills, and fostered meaningful social and academic interactions with students. Lecturer A used multimedia technology (including a Facebook-run laptop) to demonstrate and explain Microsoft Excel processes and concepts. She used summative assessment (assignments and quizzes) to assess student understanding of the technical processes of the tasks she demonstrated in class. The contradiction in Lecturer A's work activity was that although she needed to identify promptly student information gaps and misconceptions about Excel technical processes through her demonstration of concepts in class (using her Facebook-run laptop), students had no opportunities in class for practicing with technology (computers) to show this understanding. Students only executed tasks in laboratories where she was least involved since the lecturer's role in the computer laboratory was restricted to the supervision of tutors. This lack of student practice (experiential learning) during instruction became a dilemma that challenged her with regards accessing their mental structures / their level of understanding - a contradiction between subject (student' understanding) and tool-in-use (use of representational technology) (see contradiction 1 in Figure 2).

The turning point was when she deliberately made 'forced' errors during her Excel demonstrations to force students to locate her mistakes in technical problem solving. She affirmed this strategy in an interview:

We differ from social sciences where lecturers give exercises to students in groups in class to reflect on. In IS, they do it in the labs. Therefore, the only way for them to learn is for me demonstrate Excel tasks, make mistakes, and make them reflect on it. That way they learn faster (Interview 9/04/09). 
MEDIATING TOOLS- Facebook, blogs, Vula, discussion forum, multimedia

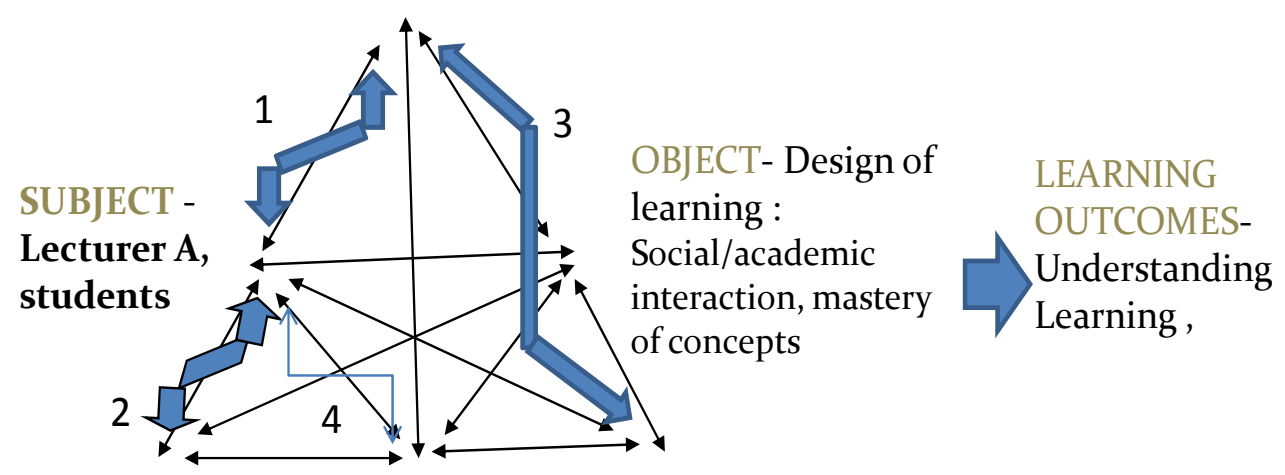

\section{RULES}

Requirement to sign in for facebook,

Requirement to use facebook for questions and answers , silence in class, raising hands , being seated, use of English

\section{COMMUNITY- ROLES-}

Facebook Learning guide, support

friends, peers, students, sharing senior students, expertise with faculty staff's students, demonstration cooperation, of concepts, control of guest lecturers, lecture space, provision technical support of lecture material

Figure 2: Lecturer A's Work Activity System

In a lecture, the conceptual difficulty of demonstrating technical subjects that demanded the novice use of computers during instruction thus complicated learning. Below is an example of the forced errors she made to 'compel' student reflection on the problem:

(The lecturer attempts to draw a pie chart and the laptop rejects her command and it clicks loudly).

Lecturer: What is wrong? (Students laugh but she keeps on demonstrating).

L: (She follows the technical steps needed.) Select-my data insert, I want it to give me a pie chart. Why is it [the laptop] refusing to give me a pie chart?

L: Why is it refusing? (Students cannot help, they remain silent).

L: How do I define my data set? It is strange. Select the data to be done, I have done that; select the design, I did that. Why then is it refusing to give me a pie chart?

(They cannot locate the error.)

L: (There is silence. No one provides a good guess.) I selected the wrong one. I should have selected this one. (She finally gets it.) Why didn't you tell me? Are you sleeping? (Students laugh.)

L: Who identified the mistake that I made? (Observation transcription 2/04/09).

The last statement demonstrates that the mistakes were deliberate. The use of forced errors constituted a shift in pedagogical practice, that is, from mere demonstration of technical processes 
(which complicated identification of student mental structures and mental shifts induced by learning) towards explicit teaching. With the continual use of this strategy as the course progressed, students started to engage with the technical problems. One example where a student identified the error is cited below:

(The lecturer is explaining the purpose of advance filters and how to calculate the risk range).

Lecturer: I have specified my criteria, but it's (the laptop) not responding. Why?

Student: Use uni-purpose.

L: I don't need that because some records will be duplicated. Why is it refusing?

S: Some say delete it, others say copy it to another location. (Students are employing trial and error. They seem to be co-operating with the lecturer).

L: So why is it refusing?

Laura: (A student raises her hand).

L: Oh, someone is awake! (She picks upon Laura.)

Laura: I am asking why you don't put the product ID so that you know the criteria first and then [...].

L: We have some intelligent chaps here. (The lecturer types [on her laptop] as the student gives directions).

L: Why didn't I think of it? (Observation transcription 9/04/09).

The above suggests that the lecturer managed to widen the object (student mastery and understanding of technical processes) by shifting from simple demonstration of technical processes to pushing students to reflect on problems through identifying her technical errors and resolving them. This allowed, on one hand, students' understanding and, on the other, permitted the lecturer to assess formatively student cognitive growth and thus resolve the contradiction.

\section{Use of Facebook for teaching}

All first, IS students were required by the IS department to sign up on Facebook and to join the department Facebook group. Lecturer A's dilemma involved the need to increase student academic participation on Facebook to support them without necessarily 'compelling' reluctant students to co-operate with this departmental requirement. That is, a contradiction between department's rule (rule) and student attitudes towards Facebook (subjects) (contradiction 2 in Figure 2). The lecturer voiced this in her debriefing with the researcher:

There are students who do not use Facebook for academic purposes so they do not benefit and are excluded. Do we make its use optional, because if we do, most students are not benefiting because I told them that their first assignment would be to register on Facebook. They did that but many never used it (Debriefing 14/05/09).

The dilemma of making Facebook use compulsory to scale up student mastery of the subject's technicalities was alienation as some created dormant Facebook accounts. On the contrary, allowing free use made the facility under-utilised as students felt under no obligation to participate. Indepth interviews with students confirmed its limited academic use:

I haven't posted anything on Facebook. I doubt if students are taking it [Facebook] seriously because everyone is up for social applications and I haven't seen anyone using it productively (Student interview 14/04/09). 
Students could have conceived the prescriptive academic use as an imposition of lecturers' 'dispositional power' (Clegg, 1989) in what many conceived as 'student controlled' spaces. This emphasis could have alienated some students who were obsessed with playful learning ('edutainment') and social networking. This is mirrored in the scepticism students harboured regarding Facebook' academic virtue:

I think nothing because it is a social thing. The content shared on Facebook is not academic, but social. It is corporeal, let's go drink and eat, which is very nice but I think there is a place for it [...] I do not think for people to organise their life is academic (Interview 20/03/09).

The turning point was when lecturer A identified this contradiction and emphasised the academic value of Facebook consultations every time she had a lecture to catalyse voluntary student participation. This shift in pedagogical practice (from imposition of 'ground rules' to persuasion) was discerned occasionally in lecturer A's address to students as she wound up her ADP lectures:

I am always on Facebook but you are not using it. I spend more time with the $X$ Class [mainstream class] who use me academically. I know if you have a problem, some of you cannot talk here or come to my office. So use Facebook for explaining your educational problems not dating (Observation transcript 21/05/09).

Widening the object of the lectures through more student involvement on Facebook worked to increase lecturer-student Facebook interaction. More students were reported to be engaging with this lecturer by the end of the second semester. She occasionally elaborated in class queries she would have addressed for some students on Facebook to increase complementarity of these spaces (Facebook and lectures). However, Lecturer A acknowledged the need to change the recruitment strategy for student Facebook participation in future:

The approach has to change next time. I am sure students opened Facebook accounts without knowing the purpose. They did it as a requirement to get marks. ${ }^{2}$ so maybe our goal for that assignment was not clearly articulated to them, and that created inclusion and exclusion. It was the genesis of creating differentiation because those who got our motive went on Facebook first specifically for that thus excluding others (Debriefing 14/05/09).

Although students were informed about the academic use of Facebook, the challenge was that a range of possibilities for effective use of these sites was not suggested to allow for lecturerfacilitated exploration. Creating such possibilities could have unlocked potential for broadened use while keeping an eye on the academic facet of Facebook interaction.

\section{Redundancies}

The use of Facebook as a consultative space ${ }^{3}$ aimed to offer a pre-emptive strategy for handling similar course-related questions that students asked. Due to student reluctance/inability to track previous online discussions for questions already answered by the lecturer ${ }^{4}$ coupled with their dependence on teacher's support, contradictions manifested in students posting redundant questions. The lecturer complained about this unanticipated contradiction between use of Facebook

\footnotetext{
${ }^{2}$ Students earned $2 \%$ to their course work for signing on Facebook and joining the Department Facebook group.

${ }^{3}$ Although it was a requirement to open a Facebook account and join the Department group, use was optional.

${ }^{4}$ Facebook discussion board and wall retained the trail of artefacts/postings of previous interactions and these were accessible to all Facebook group members.
} 
(tool) and student failure to browse prior questions (role) (see contradiction 3). In a debriefing, this lecturer grumbled:

Sometimes the $15^{\text {th }}$ student asks a question that I already addressed but they do not bother reading the questions that I have been addressing before asking [...] and thus a big problem because Facebook's purpose should be to reduce redundant questions (Debriefing 14/05/09).

We infer that academics envisioned Facebook to function as a collaborative space where metadata (artefacts) generated could be re-accessed to augment students' memory. However, many students did not check prior conversations before asking questions.

Apart from the weakness of limited browsing and reflection on previous queries, another practice that aggravated redundancies was coy students' preference for private communication with the lecturer (via her private inbox) to public online consultation (using wall or discussion board). This deprived other students of access to information exchanged during such interactions. In response to this contradiction, the lecturer rebuked these students and emphasised their use of Facebook public spaces for peers' benefit. The last statement in the lecturer's response to a student who consulted via her Facebook inbox demonstrates this:

Simply put, a system is an organized collection of parts (or subsystems) that are highly integrated to accomplish an overall goal. The system has various inputs, which go through certain processes Please use the discussion board in future because other students could use this information as well (Inbox Post 110).

This pedagogical shift compelled students to switch from private communication to public discourses in public Facebook spaces. This implicitly imposed relations of hierarchical dominance on students vis-a-vis exploring all Facebook spaces for learning. The requirement of using public spaces, however, resolved the contradiction by broadening the object as more answers became available to more students in public spaces.

\section{Collective responsibility and student academic support}

Although one lecturer handled all Facebook queries, some questions emerged from chapters taught by other lecturers thus necessitating their co-operation (for example, providing contexts in which queries emerged) when student queries related to their topics. The contradictions emerged when other lecturers failed to co-operate at all or failed to respond immediately to ensure that questions were addressed expediently. Lecturer A summarised this tension between her collaborative efforts with other lecturers (community) and her (subject) motivation to support students (see 4 in Figure 2):

The challenge is that student queries are directed to me and not lecturers who taught the topic, so it becomes difficult to address these queries. Students queried that were not taught [topic cited] so I checked who taught that topic and it was not taught. However, I could not expose my colleague because it would appear as if we were not working a collective. I e-mailed this staff but he never responded so I did not answer the students (Interview 06/08/09).

The unresolved contradiction was thus between the lecturer's (subject) responsibility to address student queries and failure of community members (community) to co-operate with her. She could not compel them to act to justify her role on Facebook owing to the doctrine of collective responsibility that demanded colleagues reinforce mutually supportive behaviour. This breakdown in collaborative processes narrowed the lecturer's objective of supporting students by lowering her expectations about the extent of support she would get from colleagues (community) during academic consultations. 


\section{Lecturer B}

Lecturer B taught the mainstream classes and the ADP students and he maintained a social presence on Facebook. Although he occasionally provided students with advice on IS course administration on Facebook, he was not immersed in routine online interaction with students. During his lectures, lecturer B however, encouraged students to direct their administration or task-related queries to the online administrator.

TOOLS: (facebook, blogs, Vula discussion

SOCIO-
CULTURAL \&
HISTORICAL
FACTORS -
English
language
mastery, ICT
literacy,
cultural capital,
cognitive
resources

RULES: institutional culture on addressivity, eq 1 status of academic actors

forums, multimedia)

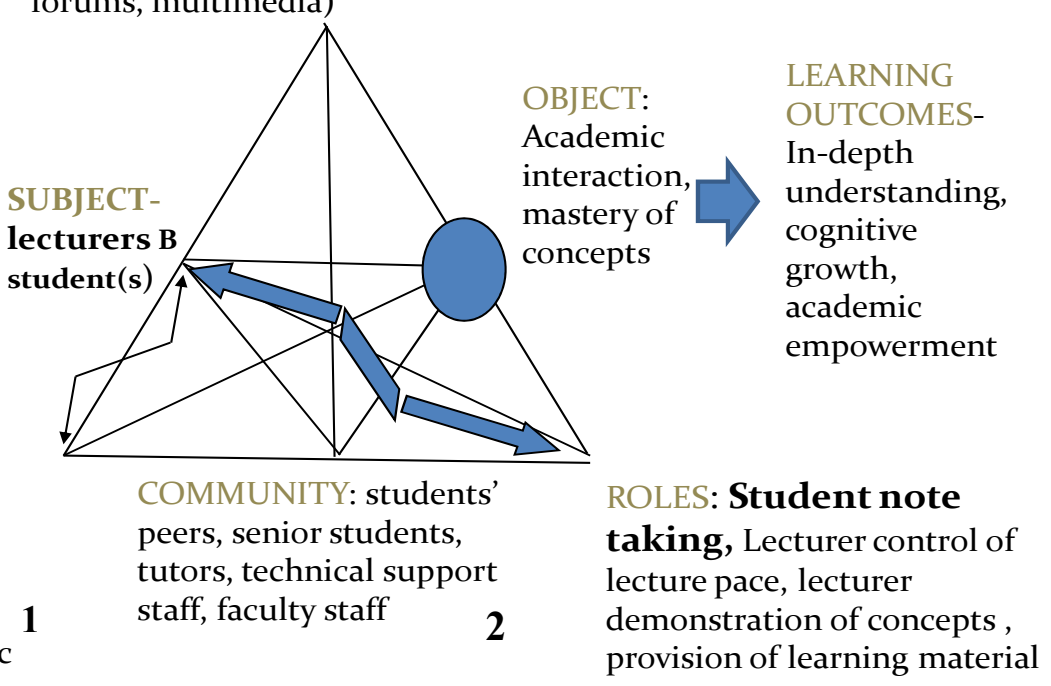

Figure 3: Lecturer B's Work Activity System

\section{Personal beliefs about academic relations and institutional learning culture}

Lecturer B noted the tension between his beliefs (subject) about what lecturer-student relationship should exist (face-to-face and on Facebook) and the learning culture perpetuated by the institution (rules) - subject-rules contradiction. He conceived a misalignment between the institution's culture on forms of address of lecturers (that seemed to negate use of titles) and the respect for lecturers as symbols of authority. He cited incidences of students booing lecturers in class and using inappropriate language on Facebook as attributable to student abuse of the university's culture of collegiality between lecturers and students. For big lectures, the lecturer bemoaned high noise levels and student lack of respect that constrained lecturer-student meaningful engagement.

The lecturer partially resolved this contradiction using persuasion/charm when admonishing inappropriate student behaviour in class and on Facebook. As Carspecken (1996, p. 131) alludes, people skilled at 'charming' win loyalty from others through the employment of culturally understood identity claims and norms. For this lecturer, the use of polite language and persuasive power ensured that students co-operated with his motives during lectures and in online consultations. Lecturer B reiterated this during a debriefing:

I cannot teach in an environment where students are shouting, capitulating on mob psychology. They know that if one student boos me, the rest will follow. I know we come from different backgrounds but when they offend me, I tell them (Debriefing 14/05/09). 
By admonishing students, the lecturer was working towards fostering a mutually-beneficial relationship with students, hence widening the object of learning.

\section{Inter-generational tensions}

The lecturer noted the tension between his expectations of students to take notes as he lectured or when he substantiated information he had discussed on Facebook, and student reluctance to do so. Inter-generational tensions emerged from the fact that lecturer B emerged from a disciplinarian academic culture where students listened to lecturers, silently taking notes. Conversely, he taught the Internet generation that grew up with interactional technology, not disposed to taking notes. This constituted a contradiction between roles (of students) and subject's expectations (lecturer). The tension therefore, manifested in the lecturer's subconscious expectations for students to behave in conformist ways he was taught. Lecturer B echoes this dilemma in a debriefing:

In lectures, students who just fold their arms puzzle me. They must write down the explanations I give because not everything that I say will be on Facebook or in the notes. Sometimes, I give them examples that are not in notes or I explain a concept better than I wrote in the notes (Debriefing 2/04/09).

This contradiction between the lecturer (subject) and students' roles of note taking (roles) was never resolved and the object remained untransformed (see contradiction 2 in Figure 3). Although his social presence assisted him in accessing firsthand the problems students had, students did not shift their classroom practice. That said, it seems Facebook brought the two generations together by training some students to contribute content in online spaces.

\section{Lecturer C}

\section{Limited contact time}

Lecturer C was not on Facebook but rather used blogs, another SNS genre. He identified the contradiction between his desire to explain Excel concepts in-depth and intensifying meaningful interactions with students on blogs on one hand, and the limited contact time that forced him to accelerate lecture pace, on the other. This constituted the contradiction between the subject (lecturer) and the rules (defined contact time). (See Figure 4.) The former implied more interactivity and heightened student construction of knowledge through blogs. The later implicitly meant lecturer acceleration of lecture pace and summarising content to finish his huge workload. Lecturer $\mathrm{C}$ recounted this dilemma in his lecture experiences:

Notwithstanding blog use, minimal lecturer-student interaction exists in class. There were over 300 students in a lecture, and although 45 minutes for lecture contact seemed much, the material to be covered within that time was a lot. Therefore, I would hurry so that I do not lag behind. I needed to balance between finishing lecture content upon which they would be tested in a tutorial and maintaining interaction that was minimal (Interview 7/08/09).

Students failed to immerse in disciplinary discourses of the subject, the contradiction was unresolved, and the object was untransformed. 


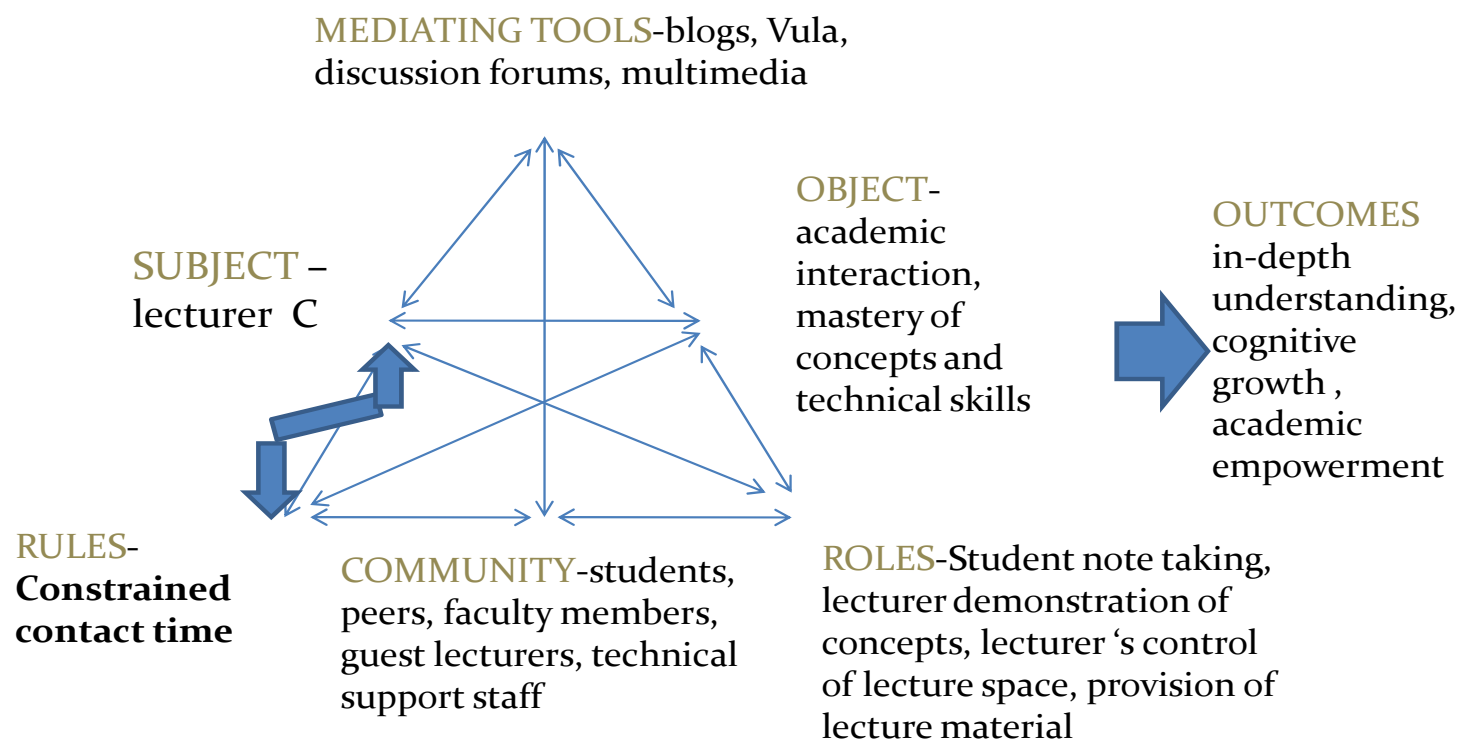

Figure 4: Lecturer C's Work Activity System

\section{Discussion}

Roth (2007) contends that the object/motive of an activity is realized through a series of goaldirected actions and underscores that goals are formulated precisely in the service of realising activities. It is important to underscore that we examined the interface between face-to-face interaction and online consultation and the object of activity in both types of interactions were related. In face-to-face interaction, the lecturers' object was conceived as the design and delivery of effective instruction that fostered their meaningful interaction with students, enabled student mastery of technical and practical concepts of the ICT course and student participation in ICT discourses. In the Facebook learning environment, the object of the activity was the lecturers' effective designing of learning environment that affords meaningful lecturer-student and student-peer interaction, student mastery of concepts, and effective participation in discourses of the discipline. The ability of lecturers to articulate the teaching and learning objects clearly is important for student learning given that students with limited prior mediated learning experiences (MLE) often have a tendency to conflate the object of learning with the materials used to achieve it, leading to learning goal displacement (Feuerstein, Rand, Hoffman, \& Miller, 1980). Hence intentionality in MLE (Feuerstein et al., 1980), in this case, lecturer's organisation of learning using instructional tools and strategies (face-to-face instruction), and Social Media (online interaction), is critical to effective student mediated learning. It is in light of the previously mentioned objects of face-toface contact and online consultation that the following contradictions that emerged from them are deliberated.

\section{Limited Experiential Learning - A Catalyst for Pedagogical Change}

Lecturer A identified a contradiction between using Facebook-enhanced laptop for the demonstration of Excel technical processes and the absence of student opportunities for practicing with technology for executing tasks during lectures. The unavailability of student mental schemas for the lecturer's formative assessment of their understanding during lectures compounded the prob- 
lem. The lag between lecturer demonstration of concepts in class and students practicals in the computer laboratories further complicated student capacity to relate lectures to lab tasks. Resultantly, this pushed Lecturer A to shift her pedagogical strategy from implicit teaching to explicit teaching through forced errors that 'compelled' students to identify the 'mistakes' that she made, making them crisper in problem identification and problem solving. This shift in pedagogical practice is consistent with Engeström $(1999$, p. 9) who emphasises disturbances and contradictions as the "motive force of change and development". This adjustment by the lecturer in response to the students' learning challenges demonstrates that the lecturer's role shifted from that of an instructor to a co-learner in a complex learning context.

While this strategy worked well in lectures given affordances for instant feedback from the lecturer, it was difficult to apply online given the volume of questions the lecturer was expected to respond to and the possibilities of less sophisticated students using the wrong answers without discernment. Using all Facebook spaces (inbox, discussion board, and the wall), students posted questions on theory-related issues, practical queries on procedures and formulae, and general course administration. Compared to other spaces, the wall was used most owing to its convenient access to students when they were busy and the relative ease with which peers could respond to queries from this space. On Facebook however, the lecturer changed her pedagogical strategy by providing background information in problem solving, providing leading questions, or detailed explanations that activated student critical thinking about the problem. This expansion of the object and scope of online interaction resonates with Engeström's (2001) conception of expansive transformation that is accomplished when the object and motive of the activity are reconceptualized to embrace a radically wider horizon of possibilities than in the previous mode of the activity. This scaffolding process demonstrates the commitment of this academic to transcend the technicist approach to technology by emphasising the pedagogical value that the technology could bring for students.

Nevertheless, sometimes detailed explanations unintentionally entrenched cycles of student dependence on educators for academic support. The contradiction above is thus a manifestation of the challenge of 'built pedagogy' (Monahan, 2002) that may stand in the way of effective technology-mediated teaching. The fact that the above contradiction was identified by Lecturer A and not by other lecturers is not surprising as she was the only regular lecturer who was more deeply involved in addressing student queries on Facebook than other lecturers. Lecturer B, who had an online presence, was marginally involved, rendering course administration support where necessary. Lecturer C only used blogs, another genre of Social Media, and not necessarily Facebook.

\section{Requirement for Conformity to Ground Rules}

The Department requirement for students to sign on Facebook was perceived by some students as undue influence on their learning behaviour in 'student controlled' spaces. Although both Lecturer A and B expressed student objection to the academic use of Facebook for fear of "surveillance," it was A who voiced the dilemma between free use and requirement for academic use of Facebook. The imposition and enforcement of these rules of engagement in lectures and online signified that pedagogy constitutes an enactment of hierarchical power. As Gowe (2002) suggests, the kind of knowledge produced in pedagogy interacts with the site's location and the techniques of power employed there. Therefore, 'pedagogical knowledge' articulated through Face-

\footnotetext{
5 'Built pedagogy' for Monahan (2002) signifies that configurations of lecture space afford as well as constrain certain teaching and learning activities. Examples are the lecture hall seats that face the front and the front centre position of podiums that reinforce the view of a 'sage on the stage.'
} 
book use was tightly coupled with 'normalisation,' a technique of power (Gowe, 2002) ${ }^{6}$ that required students to conform to department's ground rules. In pedagogy, power was negotiated between lecturers and students at two levels, namely, 1). Through normalisation - the administrative requirement to direct student actions on Facebook, 2). Students' resistance to academic use of Facebook meant that, perhaps, some conceived it as a tool for manipulation by academic oligarchy. Through non-participation, students inadvertently subverted hierarchical power by resisting the 'gaze' of academics in public online spaces - a behaviour Gowe $(2002$, p. 3) terms "surveillance." The original label of Facebook and other Social Media as self-promotion and identity management spaces and not necessarily educational environments could have informed student's negativity towards its use for academic purposes. Many students could have found in this Social Media some leverage for self-articulation and establishment of self-autonomy from perceived encroachment and "surveillance" by lecturers. The aforementioned student apathy could be attributed to this frustration and, therefore, Facebook's relevance as an instructional tool in light of this shortcoming is debatable. This contradiction was resolved by shifting from requiring to exhorting students to embrace Facebook academic networking. In light of the above, perhaps new Social Media that is compatible with academic networking and critical engagement would be necessary to augment knowledge generation.

\section{Redundancies Triggered by Information Management Challenges}

While Lecturer A and B integrated Facebook into their classroom instruction, the tensions associated with redundant questions surfaced in my debriefing with Lecturer A, possibly because she was more involved than Lecturer B with the overall administration of all the queries student posted. Redundancy was a manifestation of student failure, as active information seekers / knowledge generators, to use Facebook as an information repository where information generated in previous interactions was re-accessed to augment their memory. Students failed to employ information sifting skills to extract knowledge from previous online interactions before asking questions. Therefore, those who did not adopt Facebook as a personalised information system and peer group support system failed to appropriate it for effective academic networking. Shy and less confident students' preference for private communication (that is, the administrator's inbox) to public consultation (discussion board and the wall) aggravated redundancies. Another dilemma emerged as these students were recommended by the online administrator to use public spaces for consultations for the benefit of their peers, but in contradiction to what motivated their choice of private communication (for example, fear of ridicule by peers for asking unsophisticated questions publicly, professing sheer ignorance). As such, the requirement for public expression could have deterred some students and could have contravened their expectations for private expression of queries. This practice made Social Media incompatible with "safe" academic norms for consultation and undercut its value for some novices.

\section{Challenges to Collective Responsibility}

Given that several academic staff taught the course, staff cooperation was necessary to ensure that the online administrator understood the context in which some questions arose before giving academic support via Facebook. Some staff failed to give this contextual information or failed to respond in reasonable time to fulfil student information needs. Departments, therefore, need to gear themselves for constructive alignment with new pedagogical innovation if these innovations are to be effective in promoting learning. As the main anchor of online consultation, probably, it was

\footnotetext{
${ }^{6}$ Gowe's (2002) framework for examining power in micro settings like classrooms includes inter alia, normalisation which includes: invoking, requiring, setting or conforming to a standard, defining the normal.
} 
understandable that Lecturer A faced co-ordination problems as she was responsible for relaying to respective lecturers queries that emerged from their lectures, a responsibility in which neither Lecturer B nor C partook.

\section{Institutional Culture}

Lecturer B was a mature, more experienced academic than lecturers A and C. His reflections on student delinquencies can be attributed to his background, as a principled, no-nonsense academic groomed by a generation of disciplinarian teachers. Lecturers $\mathrm{A}$ and $\mathrm{C}$ were young academics that were being initiated into university teaching and, therefore, could easily identify with and condone the students' 'frivolous' concerns because of their age. Lecturer B was concerned about the collegial culture nurtured in this university, which unruly students inadvertently abused. On Facebook, students often marshalled sarcastic language to disapprove lecturers who gave tasks that were incongruent with lecture content and tutors who insufficiently supported them in computer laboratories. This finding reinforces Selwyn's (2007) observation that Facebook was used by less academically successful students for contesting the asymmetrical power relationships built into the institutional offline positions of student and formal school system and, therefore, afforded students with 'back-stage' opportunities to be disruptive, challenging, and resistant 'unruly agents.' While there is no sufficient evidence to demonstrate that students who challenged academic practices on Facebook were academically weak, it is undeniable that students unconsciously employed Facebook as a grievance handling mechanism in academia. Students used their 'hidden identities' to express their views on departmental academic contact.

It could be ironic that issues of class management (students booing lecturers) were raised by a male lecturer as it is usually female lecturers who often bemoan students undermining their authority because of the gender stereotypes imposed by society. That said, this lecturer's down-toearth, disciplinarian posture seems to auger well with his appeal to hierarchical authority to maintain order and mutual respect. Although Lecturer $\mathrm{A}$ and $\mathrm{C}$ were both young emerging academics, Lecturer A was more experienced than Lecturer C (this was his first year of university teaching) and, hence, was more versed with the subtleties of time management than Lecturer $\mathrm{C}$. It is therefore conceivable that Lecturer $\mathrm{C}$ emphasised lack of time for effective engagement with IS discourses. As Gutierrez \& Larson (2007) contend, school based literacies generally emphasise ahistorical and vertical forms of learning and are oriented towards weak literacies. In a social networking environment, literacies could mean the competence and ability to read, develop, interpret, and evaluate textual messages and related artefacts with a view to meaningfully construct knowledge. Ahistorical implies de-contextualisation, particularly one that fails to consider one's cultural and historical circumstances which give rise to certain learning behaviours. For students who consulted with peers and academics online, Facebook scaffolded learning by presenting opportunities for broadened academic networking and compensated the learning losses suffered in face-to-face academic delivery.

\section{Application of the Findings to Teaching and Learning in Web- enabled Environments}

This research cited limited experiential learning as one of the catalysts for the contradictions observed by Lecturer A. IS learning designers should therefore increase the hot spots (Internet access points) available in class to ensure that students can use their laptops or notebooks to access and reflect on the IS examples and answers previously given by the lecturer during lectures. More importantly, IS practitioners should give students more "epistemological access" (Morrow, 1994) to lecturer and peer-generated electronic resources on Facebook. This can involve teaching students the communicative language of the IS discipline, interactional genres on Facebook and 
making effective use of IS examples and applications of knowledge given by peers and the lecturer on Facebook.

IS academics need to move beyond explicit teaching by unpacking the world views and assumptions that underlie IS knowledge generation and its dissemination. While explicit teaching exposes the rationale behind certain IS technical procedures and processes, it is revealing assumptions embodied in knowledge frameworks, exposing the hidden power structures and rules of academic engagement that are academically empowering for the students. For example, these academics can employ Facebook as a 'collective Third Space' (Guiterrez, Baquedano-lopez, \& Tejeda, 1999) where the conceivably autonomous worldviews of the lecturers and perspectives of students intersect to bring about epistemic shifts and development. This involves the negotiation and integration of personal knowledge of students with institutional knowledge constructed by the lecturer. Different stances and perspectives in IS debates should not be conceived as detrimental but as catalysts for transformative learning and development.

Effective appropriation and deployment of IS applications necessitate the development of an academic community committed to sharing resources for collaborative generation of knowledge. This community of IS academics needs to render support and co-operation to each other to ensure that the IS (Web-enabled courses) delivers its intended outputs. While systemic tensions are inevitable, it is through their resolution that transformative learning processes unfold.

This work reported the contradiction between the institution's collegial culture and Lecturer B's convictions about the need for lecturers to be respected, and this belief was often subverted by students on Facebook when they critiqued some lecturers' teaching practices. In view of this, academics may need to engage in cultural learning with students in Web-enabled environments. Such learning could be activated through student engagement in IS disciplinary practices by drawing on empirical examples and knowledge application that is relevant to students' learning contexts. These practices could be useful for promoting a more mutually beneficial and academically friendly learning environment. Islam and Hewstone (1993) suggest that the nature of contact (contact frequency, atmosphere around contact) is associated with reduced anxiety towards an outward group, that anxiety mediates the relationship between contact and prejudice. We infer that where there is limited contact with an outward group, prejudice may arise based on the anxiety of the referent person towards the outward group. As such, increased contact with the outward group eliminates the anxiety caused by the limited familiarisation with the outward group's norms and social practices. Through persistent lecturer-student interaction using context-relevant examples and genuine practical applications of IS concepts, academics and students are able to comprehend student learning expectations, learning needs, learning goals, and teaching expectations respectively. Students are positioned to confront their anxieties and prejudices about the outward group, namely the lecturers.

Students may be required to understand the cognitive and emotional demands that accompany the shifts in interactions and engagement (in specific IS tasks) from private Facebook spaces to public spaces. In consequence, they need to be trained in thinking reflexively before posting information on public Facebook spaces, and using Facebook as a reflective information repository could contribute to realising this goal. The latter could encapsulate critical questioning of peers and lecturers, provision of informed answers to questions, and using information generated as intellectual resources for reflective dialogic interaction. While this engagement may not wipe out the generational differences in perspectives, they may lead to a shared understanding of IS platforms and applications by students and lecturers. 


\section{Further Research}

Avenues for further research include:

- Investigating the impact of Facebook in different departments across the whole university to ascertain if the above findings can be confirmed. Research into comparisons between Facebook use as a course requirement and its independent academic use by students could be conducted to establish the outcome of these different motivations of use.

- Interrogating Facebook use by lecturers of different colour but whose role on Facebook is similar can also be insightful in establishing whether different forms of lecturer-student, student-peer and student-content interactions would emerge when different lecturers (in terms of gender, age, and race) are involved as online administrators. More importantly, it would be interesting to establish the contradictions that obtain and their similarity/ difference to those that emerged in this study.

- Because Facebook use was restricted in Faculty computer laboratories during task executions (notwithstanding the student need for Facebook-enhanced support), it would be vital to establish the nature of use, forms of learning, and contradictions that emerge when Facebook interactions unfold on handheld devices like web-enabled mobile phones.

\section{Conclusion}

This study employed the Activity Theory concept of contradictions to unravel the influence of Facebook use by lecturers and students on their pedagogical strategy and learning respectively. In particular, the study demonstrated the pedagogical re-engineering and shifts in student learning enabled by the appropriation of Facebook for teaching and learning. Contradictions exhibited the dilemmas and challenges that accompanied the enactment of academic discourses in a conceivably 'students controlled' space. In particular, the limited opportunities for experiential learning in lectures and the attendant time lag between lectures and student execution of tasks in computer laboratories exposed the need for department investment in technological infrastructure (computers, laptops) to afford students the opportunity to practice technical task execution in lectures.

While the departmental requirement for student participation on Facebook was useful for generating student recruitment for online participation, unsophisticated students conceived it as an ad-

ministrative intrusion / distraction. It can be inferred that while the provision of 'ground rules' for learning with technology may make learning process more explicit for students, it is however not a panacea for the pedagogical challenges encountered in training new entrants entering university. Strategies that foster cultural development in technology-mediated learning and cultivate motivation for sustained participation should be instituted.

The other lesson is that when academics lurch in what are conceivably 'student controlled spaces' (Rambe, 2009), there is often a trade off between individual student agency and the enactment of hierarchical power. The application of this asymmetrical power should not offset possibilities for vibrant peer-based academic discourses that generate new knowledge and student reflection. Students need training in information literacy, in particular information management on social networking sites and meaningful academic engagement to scale up their self-regulation and diminish their extent of academic dependence on lecturers. 


\section{References}

Barab, S. A., Barnett, M., Yamagata-Lynch, L., Squire, K., \& Keating, T. (2002). Using activity theory to understand the systemic tensions characterizing a technology-rich introductory astronomy course. Mind, Culture, and Activity, 9(2), 76-107.

Bishop-Russell, J., Dubord, M., Hansen, E., \& Webster, K. (2006). Acknowledging a campus.com(munity): [theFacebook] and diversity college. University of Maine. Retrieved March 13, 2009 from www.studentaffairs.com/ves/2006entries/UniversityofMaine.ppt.

Boyd, D. (2007). Social network sites: Public, private, or what? Knowledge Tree, 13, May. Retrieved June 13, 2008, from http://kt.flexiblelearning.net.au/tkt2007/?page id=28

Carspecken, P. F. (1996). Critical ethnography in educational research: A theoretical and practical guide. New York: Routledge.

Charnigo, L., \& Barnett-Ellis, P. (2007). Checking out Facebook.com: The impact of a digital trend on academic libraries. Information Technology and Libraries, 23-34.

Chickering, A. W., \& Reisser, L. (1993). Education and identity. (2nd ed). San Francisco: Jossey-Bass.

Clegg, S. (1989). Frameworks of power. London: Sage.

Dabbagh, N., \& Kitsantas, K. (2005). Using web-based pedagogical tools as scaffolds for self-regulated learning. Instructional Science, 33(5-6), 513-540.

DiMicco, J. M., \& Millen, D. R. (2007). Identity management: Multiple presentations of self in Facebook. GROUP'07, Sanibel Island, Florida: USA, November 4-7.

Ellison, N. B., Steinfield, C., \& Lampe, C. (2007). The benefits of Facebook "friends": Social capital and college students' use of online social network sites. Journal of Computer Mediated Communication, 12(4). Retrieved March 3, 2009, from http://jcmc.indiana.edu/vol12/issue4/ellison.html

Engeström, Y. (1987). Learning by expanding: An activity-theoretical approach to developmental research. Helsinki: Orienta-Kosultit Oy, Finland.

Engeström, Y. (1999). Innovative learning in work teams: Analysing cycles of knowledge creation in practice. In Y. Engeström, R. Miettinen, \& R. L. Punamaki (Eds.), Perspectives on activity theory. Cambridge University Press.

Engeström, Y. (2000) Activity theory as a framework for analyzing and redesigning work. Ergonomics, 43(7), 960-974.

Engeström, Y. (2001). Expansive learning at work: Toward an activity theoretical reconceptualisation. Journal of Education and Work, 14(1), 133-156.

Feuerstein, R., Rand, Y., Hoffman, M., \& Miller, R. (1980). Instrumental enrichment. Baltimore, MD: University Park Press.

Gowe, J. (2002). Some certainties in the uncertain world of classroom practice: An outline of a theory of power relations in pedagogy. Paper prepared for presentation at the Annual Meeting of the Australian Association for Research in Education, December 2-5, Brisbane.

Graetz, K. (2006). The psychology of learning environments (Reprinted). In D. Oblinger (Ed), Learning spaces. EDUCAUSE, E-book. Retrieved June 13, 2010, from http://www.educause.edu/learningspaces

Grude, A., Scholl, M., \& Thompson, R. (2006). Privacy on Facebook. Computer Supported Cooperative Work, SI689, 1-17.

Gutierrez, K., \& Larson, J. (2007). Discussing expanded spaces for learning. Profiles and perspectives. Language Arts, 85, 69-77.

Gutierrez, K. D., Baquedano-lopez, P. \& Tejeda, C. (1999). Rethinking diversity: Hybridity and hybrid language practices in the third space. Mind, Culture, and Activity, 6(4), 286-303. 
Hasu, M., \& Engeström, Y. (2000). Measurement in action: An activity-theoretical perspective on producer-user interaction. International Journal of Human Computer Studies, 53, 61-89.

Hewitt, A., \& Forte, A. (2006). Crossing boundaries: Identity management and student/faculty relationships on the Facebook. CSCW'06, Banff, Alberta: Canada, 1-2.

Islam, M. R., \& Hewstone, M. (1993). Dimensions of contact as predictors of intergroup anxiety, perceived out-group variability, and out-group attitude: An integrative model. Personality and Social Psychology Bulletin, 19, 700-710.

Jaffer, S., Ng'ambi, D., \& Czerniewicz, L. (2007). The role of ICTs in higher education in South Africa: One strategy for addressing teaching and learning challenges. International Journal of Education and Development using Information and Communication Technologies, 3(4). 131-142. Retrieved May 09, 2010, from http://ijedict.dec.uwi.edu/include/getdoc.php?id=2566\&article=421\&mode $=$ pdf

Koszalka, T. (2002). A cultural historical activity (CHAT) analysis of technology integration: Case study of two teachers. Syracuse University, 492-502.

Kozulin, A., Gindis, B., Ageyev, V., \& Miller, S. (Eds.) (2003). Vygotsky's educational theory in cultural context. Cambridge: Cambridge University Press.

Kuutti, K. (1996). Activity theory as a potential framework for human-computer interaction research. In B. A. Nardi (Ed.), Context and consciousness: Activity theory and human-computer interaction (pp. 1744). Cambridge, MA: The MIT Press.

Leadbeater, C. (2007). Social software for social change. A discussion paper for the Office of Third Sector, July 2007. Retrieved July 20, 2010, from http://www.charlesleadbeater.net/cms/xstandard/social_software.pdf

Madge, C., Meek, J., Wellens, J. \& Hooley, T. (2009). Facebook, social integration and informal learning at University: 'It is more for socialising and talking to friends about work than for actually doing work.' Learning, Media and Technology, 34(2), 141-155.

McIntyre, S. (2008). Leap of faith: Effective steps for establishing online collaborative learning initiatives. Proceedings of the $3^{\text {rd }}$ International Conference on E-learning. Academic Publishing Limited, Reading, UK.

Monahan, T. (2002). Flexible space and built pedagogy: Emerging IT embodiments. Inventio, 4(1), 1-19. Retrieved from http://doit.gmu.edu//inventio/issues/Spring_2002/Monahan_1.html

Moore, D. (2010). Join the conversation: How (some) South African universities are using social media. Retrieved August 20, 2010, from http://www.weblearning.co.za

Morrow, W. (1994). Entitlement and achievement in education. Studies in Philosophy and Education, 13, $33-37$.

Murphy, E., \& Rodríguez-Manzanares, M. A. (2008a). Contradictions between the virtual and physical high school classroom: A third-generation Activity Theory perspective. British Journal of Educational Technology, 39(6), 1061-1072.

Murphy, E., \& Rodriguez-Manzanares, M. A. (2008b).Using activity theory and its principle of contradictions to guide research in educational technology. Australasian Journal of Educational Technology, 24(4), 442-457.

Ng'ambi, D., \& Rambe, P. (2008). Barriers to students' use of electronic resources during lectures. Conference paper presented at the Sacla Conference, July 13-16, 2008.

Njenga, J. K., \& Fourie, L. C. (2010). The myths about e-learning in higher education. British Journal of Educational Technology. 41(2), 199-212. Retrieved September 15, 2010, from http://onlinelibrary.wiley.com/doi/10.1111/j.1467-8535.2008.00910.x/pdf

Pargetter, R., McInnis, C., James, R., Evans, M., Peel, M. \& Dobson, I. (1998). Transition from secondary to tertiary: A performance study. Canberra: AGPS. Retrieved July 15, 2010, from http://www.deetya.gov.au/highered/eippubs.htm 
Rambe, P. (2009). The impact of using social networking sites on academic relations and student learning in university setting. Doctoral dissertation, University of Cape Town, 2009.

Republic of South Africa. (1997, August 15). Education White Paper 3- A Programme for Higher Education Transformation, Government Gazette, 4 no. 18207.

Roth, W. (2007). The ethico-moral nature of identity: Prolegomena to the development of third-generation Cultural-Historical Activity Theory. International Journal of Educational Research, 46, 83-93.

Roth, W., \& Lee, Y. (2004). Interpreting unfamiliar graphs: A generative, activity theoretic model. Educational Studies in Mathematics, 57(2), 265-290.

Roth, W., \& Lee, Y. (2007). Vygotsky‘s neglected legacy: Cultural-historical activity theory. Review of Educational Research, 77(2), 186-232.

Russell, D. L., \& Schneiderheinze, A. (2005). Understanding innovation in education using activity theory. Educational Technology and Society, 8(1), 38-53.

Salmon, G. (2007). Learning futures. Keynote address, ConnectEd Conference, University of New South Wales.

Schensul, S. L., Schensul, J. J., \& LeCompte, M. D. (1999). Essential ethnographic methods: Observations, interviews and questionnaires (pp. 1-7), New York: Row and Littlefield Publishers.

Selwyn, N. (2007). Web 2.0 applications as alternative environments for informal learning-a critical review: Using ICT to change impact and outcomes. A paper prepared for OECD-KERIS expert meetingSession-Alternative learning environments in practice. Institute of Education, University of London.

Shen, P. D., Lee, T. H., \& Tsai, C. W. (2007). Applying web-enabled problem-based learning and selfregulated learning to enhance computing skills of Taiwan's vocational students: A quasi-experimental study of a short-term module. The Electronic Journal of e-Learning, 5(2), 147-156.

Stetsenko, A. (2005). Activity as object related: Resolving the dichotomy of individual and collective planes of activity. Mind, Culture and Activity, 12(1), 70-88.

Tan, F. B. \& Chan, H. (1997). Managing self-instructed learning within the IS curriculum: Teaching learners to learn. Informing Science: the International Journal of an Emerging Transdiscipline, 1(1), 1-7. Retrieved from http://www.inform.nu/Articles/Vol1/v1n1p1-7.pdf

Toomela, A. (2008). Activity Theory is a dead end for methodological thinking in cultural psychology too. Culture and Psychology, 14(3), 289-303.

Van der Merwe, A. \& Mouton, J. (2005). Integrating ICTs into the teaching and learning environment: An investigation of lecturer perceptions of possible barriers and incentives. Perspectives in Education, 23(4), 19-37.

Vygotsky, L.S. (1981). The genesis of higher mental functions. In J.V. Wertsch (Ed.), The concept of activity in Soviet psychology (pp. 144-188), Armonk, NY: Sharpe. (Original work published in 1930.)

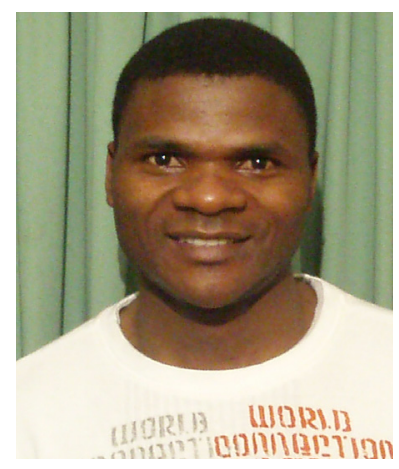

\section{Biography}

Dr. Patient Rambe holds a PhD in Education Technology from the Univesity of Cape Town. His research interest is in the innovative pedagogical use of social media and appropriation of emerging Webbased technology in resource-constrained teaching and learning environments. 